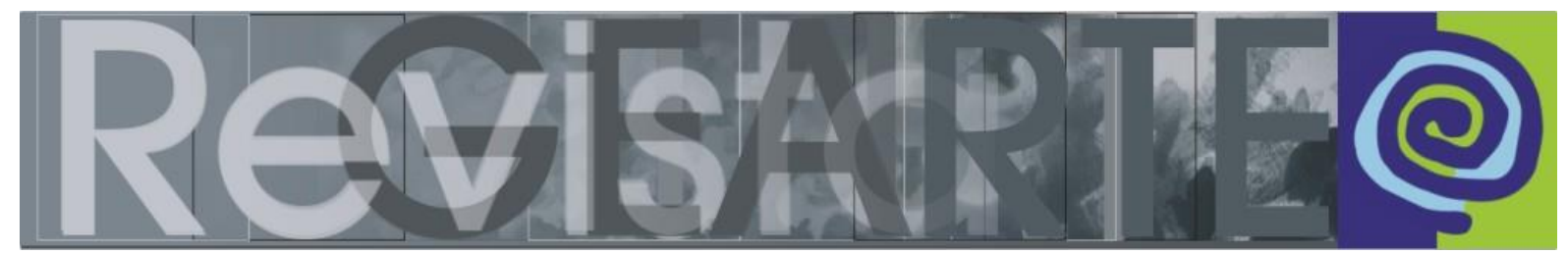

ISSN 2357-9854 | e-ISSN 2596-3198 (online)

\title{
Nombres retratados. Historias dibujadas transfronterizas y transgeneracionales.
}

\author{
Noemí Peña-Sánchez \\ (Universidad de La Laguna - ULL, Tenerife, España) \\ Rita Noguera Ricardi \\ (Jugar con Arte Madrid, España)
}

\begin{abstract}
RESUMEN - Nombres retratados. Historias dibujadas transfronterizas y transgeneracionales - Presentamos una experiencia artística desarrollada con estudiantes de la Universidad de La Laguna en Tenerife (España) y niñas y niños de Mid-Peninsula Boys \& Girls Club en San Mateo, California (EEUU). El interés común de las educadoras era fomentar experiencias culturalmente diversas en educación artística y que implicaran a los contextos educativos en los que nos encontrábamos. Buscamos generar experiencias vitales a través de la educación artística y en las que la identidad figura como protagonista. Nombres retratados es un proyecto transfronterizo que implica a los participantes de estos territorios, y con los que iniciamos una comunicación basada en creaciones artísticas que retratan nombres de personas desconocidas. Se planifica a partir de una serie de encuentros en los que imaginamos una apariencia a través de un nombre, nombres que transitan aquí y allá. Cada diálogo visual despierta pensamientos, fomenta la imaginación y alimenta la intriga de saber con quién nos comunicamos. Todas estas creaciones generan conversaciones que suponen un cúmulo de pequeños relatos emparejados y en su conjunto se construye sin quererlo una verdadera historia.
\end{abstract}

PALABRAS CLAVE

Diálogo visual. Retratos. Identidad. Contextos educativos. Diversidad cultural.

RESUMO - Nomes retratados. Histórias transfronteiriças e transgeracionais desenhadas Apresentamos uma experiência artística desenvolvida com estudantes da Universidade de La Laguna em Tenerife (Espanha) e com meninas e meninos do Mid-Peninsula Boys \& Girls Club em San Mateo, Califórnia (EUA). O interesse comum dos educadores era promover experiências culturalmente diversas no ensino da arte e envolver os contextos educacionais em que estávamos. Buscamos gerar experiências vitais por meio do ensino da arte, nas quais a identidade aparece como protagonista. Nomes retratados é um projeto transfronteiriço que envolve os participantes desses territórios com quem iniciamos uma comunicação baseada em criações artísticas que retratam nomes de pessoas desconhecidas. Se planeja a partir de uma série de encontros nos quais imaginamos uma aparência através de um nome, nomes que transitam aqui e lá. Cada diálogo visual desperta pensamentos, estimula a imaginação e alimenta a curiosidade de saber com quem nos comunicamos. Todas essas criações geram conversas que supõem um grupo de pequenas histórias, as quais, em seu conjunto, constituem, sem querer, uma verdadeira história.

PALAVRAS-CHAVE

Diálogo visual. Retratos. Identidade. Contextos educacionais. Diversidade cultural.

ABSTRACT - Portrayed names. Cross-border and transgenerational drawn stories - We present an artistic experience developed with students from the University of La Laguna in Tenerife (Spain) and pre-teen girls and boys from the Mid-Peninsula Boys \& Girls Club in San Mateo, California (USA). The educators had a common interest in fostering culturally diverse experiences in artistic education while involving the educators' educational contexts. We sought to generate life experiences through Art Education and with the individual's identity playing the key role. Portrayed 


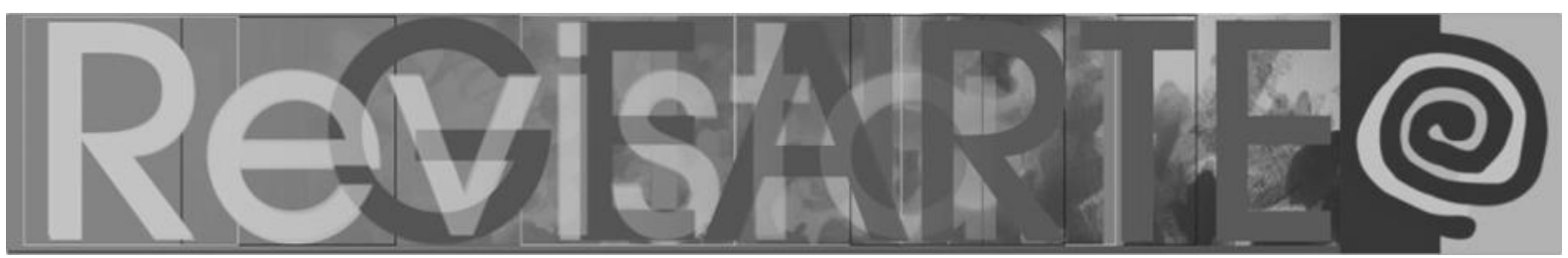

Names is a cross-border project that involved the participants in the territories, and with whom we initiated a communication based on artistic creations that portrayed the names of unknown persons. It was planned as a series of encounters in which we imagined a person's appearance based on a name, and the names traveled to and from each participating territory. Each visual dialogue prompted thoughts, fostered the imagination, and sparked curiosity about the other person. All these creations generated ongoing conversations that composed a body of small paired stories and, as a whole, a broader narrative.

KEYWORDS

Visual dialogue. Portraits. Identity. Educational settings. Cultural Diversity.

\section{Introducción}

Nuestros nombres nos identifican definiendo quiénes somos y conforman una imagen simbólica con la que nos definimos. Nuestros nombres expresan también nuestras subjetividades. Independientemente del territorio en el que nos encontremos, de la generación a la que pertenezcamos y de cuál sea nuestra cultura, todas y todos tenemos un nombre que nos identifica, nexo con el que ambas educadoras hemos construido esta historia con diálogos, misterio y sorpresa, ingredientes para preparar una experiencia educativa común. Como educadoras compartíamos el entusiasmo de diseñar una iniciativa artística junto a nuestros estudiantes en cada uno de los territorios - España y Estados Unidos - y contextos. Los nombres eran también protagonistas del cuento titulado Alma (MARTÍNEZ-NEAL, 2018), con el cual nos inspiramos para desarrollar la experiencia de Nombres retratados.

El relato que aquí contamos describe las características de esos dos territorios; dos contextos educativos diversos en los que planteamos una experiencia de intercambio como aprendizaje artístico y humano. También queremos subrayar el relato de cómo se genera esta experiencia entre educadoras. Esta colaboración requiere diálogo, comunicación y discusión de ideas entre ambas para diseñar y adecuar la experiencia a cada contexto. También hemos querido cuidar el formato narrativo de este texto estructurándolo en tres encuentros que viajan entre territorios de aquí de allá y finaliza con un desenlace en el que desvelamos las identidades de todos esos nombres implicados. Al igual 


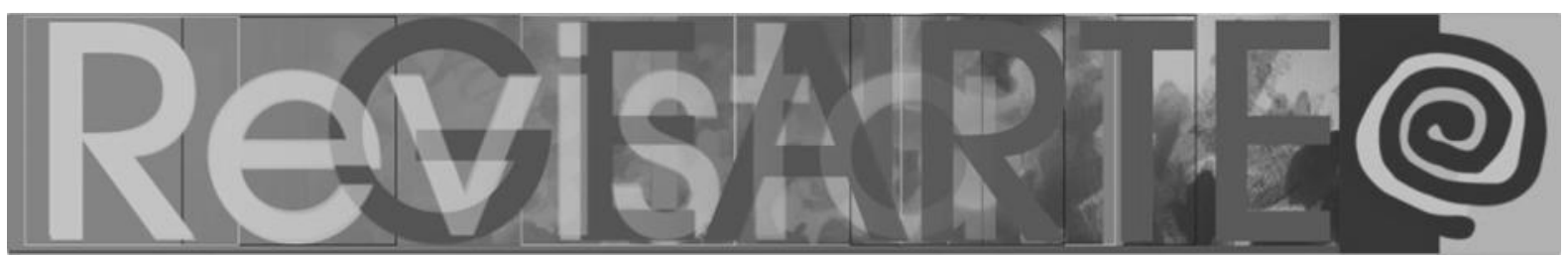

que la experiencia desarrollada se fue tejiendo con cada encuentro y con cada diálogo, este texto se ha ido entretejiendo igualmente con nuestra propia escritura.

Sin duda, la creación adopta una función comunicativa clave, al convertir la representación en el idioma común con el que pensamos y nos expresamos. Aunque los participantes hablan lenguas diversas, en el diálogo visual que se establece éstas son desconocidas haciéndose invisibles a los ojos de la otra persona. Para Hernández (2012) la lengua que hablamos es tan solo una parte de nuestra identidad a la que añade el contexto como subjetividad. "El contexto también tiene importancia, porque es lo que hace que se produzca un discurso, entendido como formas de hablar, ver, pensar y comportarse que hacen posible reconocer y ser reconocido por otros" (HERNÁNDEZ, 2012, p. 70). Es indudable que ese contexto va implícito en todo aquello que creamos porque hacemos visual toda esa subjetividad que nos identifica. En cada creación hay elementos conscientes e inconscientes que representamos y comunicamos.

\section{La diversidad cultural en el aprendizaje artístico}

Partimos de dos contextos educativos diferenciados, tanto por el tipo de formación que se imparte como por la variedad de edades que comprende cada uno de estos espacios y, cómo no, por la riqueza multicultural existente. Si bien en ambos casos la educación artística se convierte en protagonista de una experiencia creadora, accesible y adecuada a todas las personas que involucramos, destacamos la participación de un contexto no formal como es el Mid-Peninsula Boys \& Girls Club (MPBGC) de San Mateo, en California, es clave, pues posibilita el desarrollo de iniciativas de creación artística con niñas y niños de diferentes edades, alejado de ese posicionamiento académico y con la libertad para emprender acciones adaptadas a las necesidades y demandas del grupo. En contraposición, la Universidad de La Laguna, en Tenerife, y, concretamente, estudiantes que se preparan para ser futuros educadores a quienes les brindamos una experiencia que conecta sus vidas con las de otras personas a través de la 


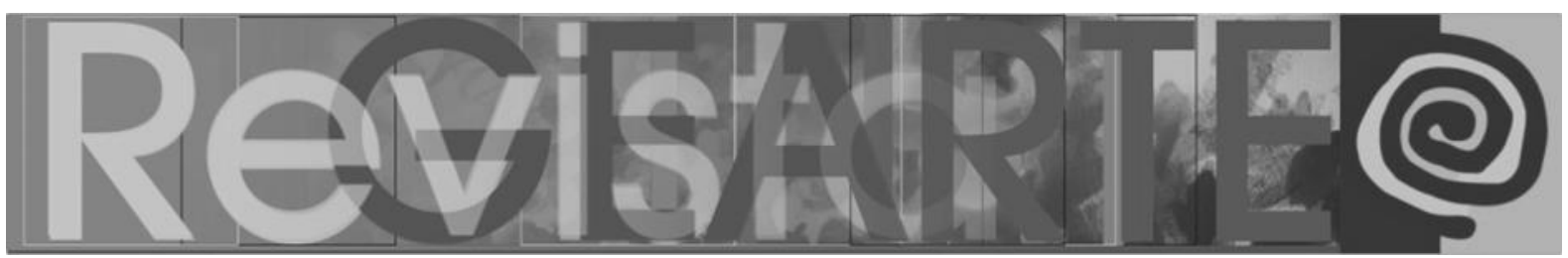

educación artística. En este sentido, no podemos estar más de acuerdo con Stuhr (2003) quien subraya la necesidad de establecer vínculos de aquello que se enseña con sus propias vidas porque es precisamente ese proceso identitario lo que hace posible dar valor a una educación artística que vaya más allá de los saberes procedimentales.

\begin{abstract}
La educación artística, al igual que el resto de las materias, debe estar íntimamente conectada con las vidas de los estudiantes; y por tanto del currículum, porque de esta conexión entre la vida del estudiante y sus mundos se concibe un proceso en continuo y no un producto. (STUHR, 2003, p. 303).
\end{abstract}

Además, dichos contextos educativos provienen de culturas diversas, la de los niños y niñas residentes en California (EEUU), ya en sí una realidad multicultural y multilingüística, con la de estudiantes universitarios jóvenes y adultos en las Islas Canarias (España). La multiculturalidad, para Banks y Banks (2010), define a cada individuo como un ser social que se identifica con diferentes grupos que definen su identidad, tales como la nacionalidad, la etnicidad, el género, la clase social, etc. La variedad generacional también debemos entenderla como otro grupo cultural, ya que cada una de ellas, bien sea generación $\mathrm{X}, \mathrm{Y}$ ○ $\mathrm{Z}$ han vivido bajo circunstancias históricas, sociales y como no tecnológicas que los identifican culturalmente. Queremos así subrayar como característica, la inevitable presencia de la diversidad cultural en la experiencia realizada. Además del salto generacional existente entre los grupos participantes y que indudablemente modelan el modo en cómo nos comunicamos con la otra persona que no conocemos. A cada niña, niño, joven o adulto de aquí y de allá se le propone establecer un diálogo visual con otra persona a través del dibujo, lenguaje que adoptamos como medio de comunicación. El diálogo se establece a través de la creación de dibujos y de la recepción de otros que hablan de ellos y ellas mismas, generando así una comunicación. La información sobre quiénes son esas otras personas se va desvelando con cada encuentro y con cada creación y, cómo no, al compartirla con el resto del grupo. Con esta experiencia conscientemente fomentamos valores como la equidad y con el propósito de anular cualquier tipo de 


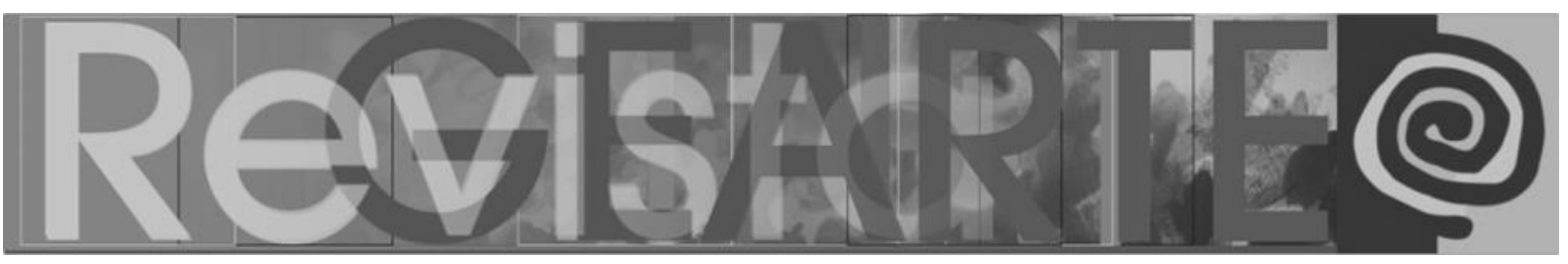

discriminación y poniendo el énfasis de promover esa diversidad cultural. "El gran objetivo de una educación multicultural es ayudar a los estudiantes a desarrollar el conocimiento, las actitudes y habilidades necesarias para funcionar en su propia microcultura, en la macrocultura de EEUU y en la comunidad global." (BANKS; BANKS, 2010, p. 25)

\section{Contextos implicados}

El primer contexto donde ha ocurrido la experiencia es en San Mateo, ubicado en la costa oeste de California, Estados Unidos, en un espacio denominado Mid-Peninsula Boys and Girls Club (MPBGC), un club autónomo afiliado a la organización nacional Boys \& Girls Clubs of America (BGCA).

MPBGC destaca por ser una organización sin ánimo de lucro que ha servido a niñas, niños y jóvenes desde 1955. Su misión es inspirar y permitir a todos los jóvenes alcanzar su pleno potencial como ciudadanos productivos, responsables y solidarios.

En este contexto educativo no reglado, Rita ha realizado talleres de arte como voluntaria. El principal objetivo de los talleres es proporcionar actividades creativas, contextualizadas a su entorno y intereses, utilizando variedad de materiales que son donados al centro.

A los talleres de Rita acudían aproximadamente quince estudiantes la gran mayoría niñas y niños de entre siete y doce años. Muchos de los asistentes eran de Estados Unidos, aunque sus familias eran originarias de otros países, lo que daba lugar a que las personas participantes hablaran otras lenguas además del inglés, como el español y el portugués.

El número de participantes de cada taller podía variar en las diferentes sesiones de cada taller, lo que nos llevó en ocasiones a adaptar los procesos de trabajo a los asistentes a cada sesión del taller. 


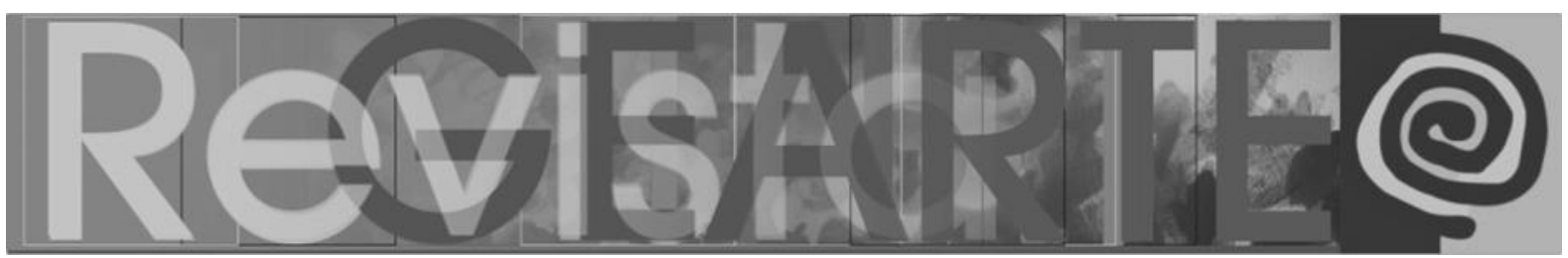

El otro contexto implicado ha sido la Universidad de La Laguna (ULL), institución académica que cuenta con más de dos siglos de historia y una amplia oferta de titulaciones de grado y posgrado. Su ubicación, Tenerife, es una de las Islas Canarias envueltas por el Océano Atlántico. Precisamente, su localización entre continentes hace que este centro de estudios superiores público tome ventaja de esa posición estratégica.

Nuestros estudiantes de Máster en Formación del Profesorado de Educación Secundaria y Bachillerato en el ámbito del Dibujo, el Diseño y las Artes Plásticas son los protagonistas de la experiencia enmarcada dentro de la docencia de la asignatura Aprendizaje y Enseñanza de la mencionada especialidad. Nuestro grupo de veintidós estudiantes son en su mayoría canarios, aunque hay estudiantes que nacieron en países de Latinoamérica, pero afincados en la isla. Cabe mencionar que su gran mayoría han estudiado Bellas Artes u otras titulaciones afines que les permiten cursar estos estudios y ejercer como educadores artísticos. Estos estudios resultan ser una opción de futuro, al ser una formación didáctica habilitante para ejercer como profesoras y profesores de Dibujo, Diseño y Artes Plásticas en las enseñanzas obligatorias y profesionales en centros educativos nacionales.

Podemos comprobar como ambos contextos están bien diferenciados, tanto por el tipo de formación que se imparte, por las características de los participantes, por las cualidades específicas de cada territorio y la gran distancia que les separa. Aún así, nos planteamos convertir esas desventajas en ventajas para desarrollar una experiencia transfronteriza y transgeneracional.

\section{Compartiendo experiencias entre educadoras: de cuentos y relatos acerca de la identidad}

En una charla telefónica Rita y Noemí empiezan a contar su último proyecto en el aula. Rita inició en MPBGC una propuesta a partir de un cuento titulado Alma de la autora Juana Martínez-Neal (2018, p. 31). "Alma siente curiosidad por su 


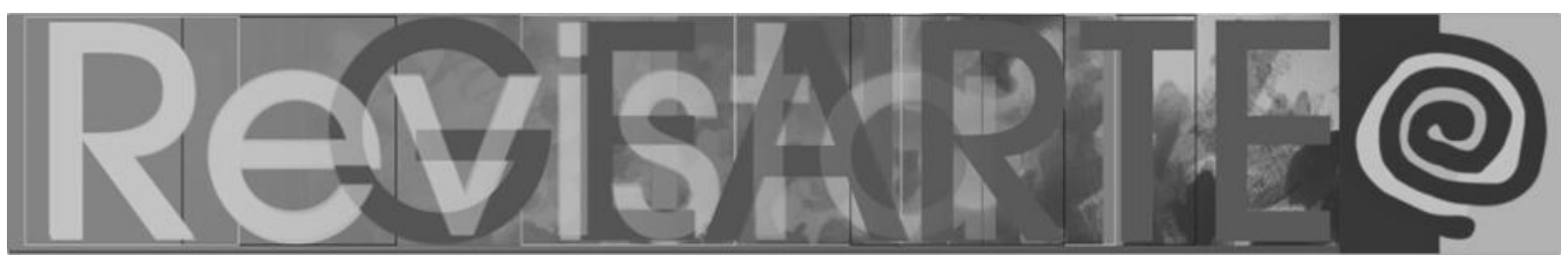

nombre largo, por lo que su papá le cuenta a su hija su gran historia." Esta es la frase de la contraportada que presenta el cuento y con la que la autora hace dos preguntas cuando cierra el cuento: “¿Cuál es la historia de tu nombre? ¿Qué historia te gustaría contar?”.

Estas cuestiones nos han inspirado para hablar y reflexionar en el taller acerca de la importancia de nuestros nombres. No hay duda de que cada nombre encierra un relato sobre quiénes somos como atributo inseparable a nosotros mismos. En el taller les propusimos a las niñas y niños de MPBGC que crearan su propio libro con la historia de sus nombres. Las revelaciones compartidas mostraban las diferentes formas de percibir y sentir que los participantes narraban en sus historias con nombres, destacando aquí algunas de ellas:

- When I was older I wanted to change my name, Aurora. (Anniyah).

_ Mi papá me llama Pía. Mi mamá me llama Mona. Mi padrino me llama Chochis. Mi madrina me llama negra. Mi tío me llama Chochis también. (Sofía).

_ Me gusta mi nombre porque se empieza con una $V$ y una $V$ es rara. (Vida).

_ My name is too big for me. (Rosalie).

_ My parents named me that because of my grandpa Renato. (Renata).

Figura 1 - Talleres que realizan el libro de sus nombres (izquierda), una página del libro de Susan (derecha)
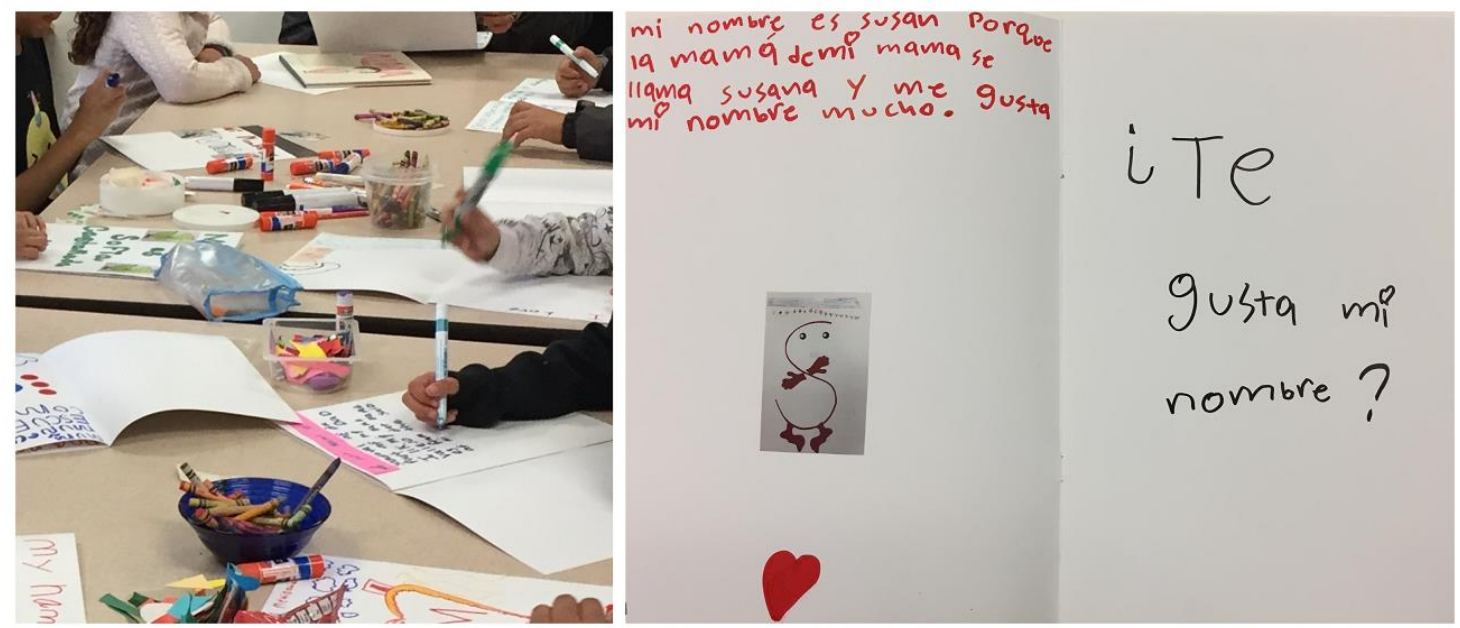

Fuente: Archivo de las autoras, 2019.

PEÑA-SÁNCHEZ, Noemí; NOGUERA RICARDI, Rita. Nombres retratados. 


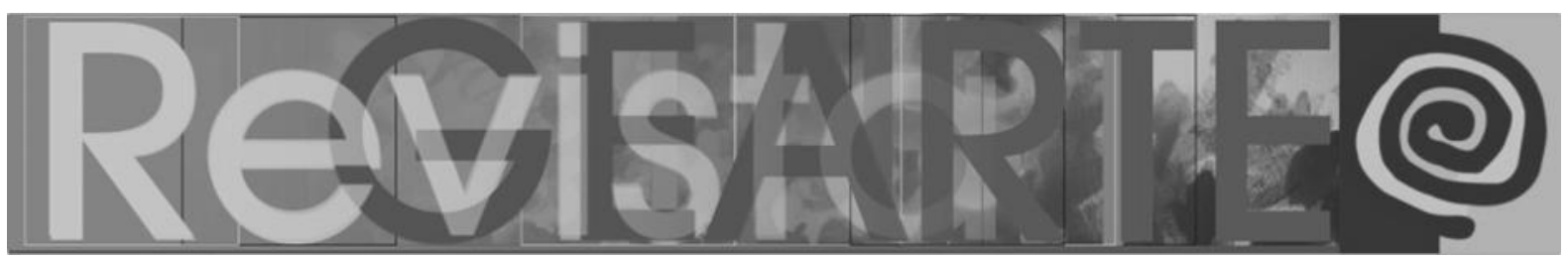

Durante el proceso, incluso decidimos contactar y compartir con la autora del cuento el interés que los nombres habían despertado en los niños y niñas. La autora envió un mensaje dirigido a las niñas y niños del taller, el cual llevaron a casa junto con el libro que habían realizado:

\begin{abstract}
Queridos chicos y chicas: muchísimas gracias por darme la oportunidad de conocer las historias de sus nombres. ;Sus dibujos son tan lindos! Ahora que ya conocen las historias de sus nombres, pueden compartirlas con amigos y familiares. También pueden preguntarles a ellos cuál es la historia detrás de sus nombres. No hay mejores momentos que aquellos compartidos conociendo más a quienes apreciamos y queremos. Nuestros nombres son una parte tan importante de quienes somos. Es importante conocer las historias detrás de ellos. ¡Sigan escribiendo y pintando! (MARTINEZ-NEAL, comunicación personal, 14 febrero, 2019)
\end{abstract}

El trabajo realizado en esos pequeños libros a partir del cuento Alma era sin duda autobiográfico, lo cual resultó tener una estrecha relación con el proyecto que los estudiantes universitarios de la ULL estaban desarrollando en nuestra asignatura. Durante todo su desarrollo elaboraban su autobiografía artística con la finalidad de redescubrir cuál había sido la formación artística recibida a lo largo de toda su etapa educativa. Esta búsqueda de creaciones despertaba indudablemente recuerdos de infancia, experiencias significativas vividas, una mirada consciente hacia producciones artísticas realizadas a lo largo de sus vidas. A través de esta conexión biográfica y de estos reencuentros identitarios, decidimos explorar cómo nuestros propios nombres podrían generar también una imagen simbólica, otra mirada sobre nosotros mismos a través de los ojos desconocidos de aquellas niñas y niños del MPBGC.

Del mismo modo, para los niños y niñas de MPBGC resultaba igualmente enriquecedor seguir indagando en sus nombres desde otra mirada e imaginando todo lo que un nombre nuevo y además de alguien desconocido puede llegar a evocar. No cabe duda, que esa multiculturalidad existente entre los niños, niñas y estudiantes se verá indudablemente reflejada a través de sus nombres, las diferencias generacionales de todos y todas ellas serán huellas implícitas en sus dibujos y los lenguajes e idiomas irán revelando poco a poco las identidades y culturas de cada territorio. El dibujo será precisamente el lenguaje elegido para 


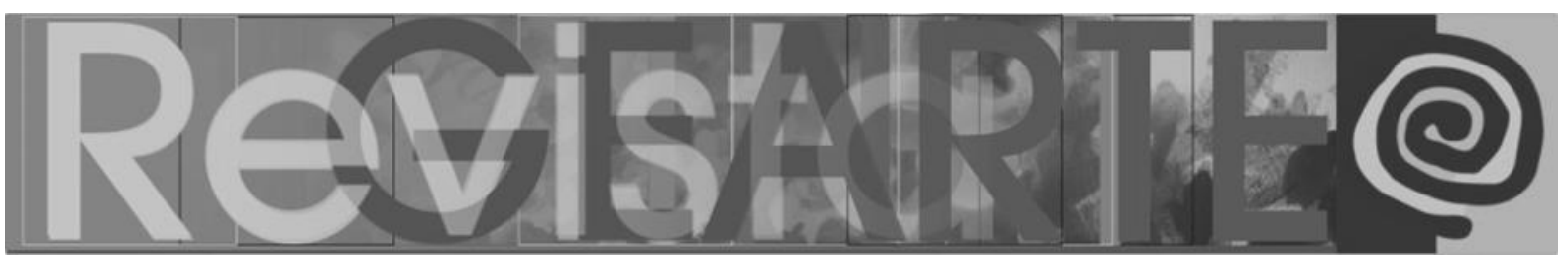

esta comunicación visual transfronteriza en la que el misterio y la expectativa estarán presentes en cada una de las sesiones experiencia.

\section{Comenzando la historia de Nombres retratados}

Hemos querido estructurar esta historia transfronteriza, transcultural y transgeneracional como si de una narrativa se tratase y en la que los nombres son protagonistas. El relato ahora descrito se fue tejiendo a medida que todos los personajes, nuestros queridos estudiantes, niñas y niños iban contribuyendo espontáneamente en cada acción, sesión que planificamos conjuntamente y a la distancia. Los diálogos y conversaciones entre las autoras y educadoras Rita (San Mateo, EEUU) y Noemí (Tenerife, España) fueron necesarios para retroalimentarnos, saber adecuar nuestras intervenciones y entender cómo proseguir los encuentros en cada contexto y cómo compartir todas esas creaciones que se iban desarrollando. Conscientes de las limitaciones y ventajas de cada escenario o contexto de la narrativa, todo se fue desarrollando con la incógnita de no saber quiénes eran aquellas personas que nos dialogan con dibujos y las que además conocen nuestros nombres. Cada encuentro es un relato entre aquí y allá que se irá desvelando hasta llegar al desenlace final.

\section{Primer encuentro: retratar a veintidós nombres desconocidos}

La importancia de nuestros nombres abría una nueva etapa en el taller de MPBGC, ya que veintidós nombres diferentes aparecieron, sin saber quiénes eran, la edad que tenían o de dónde venían. Rita les propuso dibujar cómo sería esa persona desconocida tan solo sabiendo su nombre, lo que generó curiosidad y algunos cuestionamientos. Era evidente que el género desvelado por sus nombres fue lo único que pudieron identificar, sintiendo predilección por dibujar a alguien de su mismo género.

La sesión mantuvo una atmósfera enigmática al pensar lo que ocurriría con aquellos retratos de nombres desconocidos. Las expectativas eran desconcertantes 


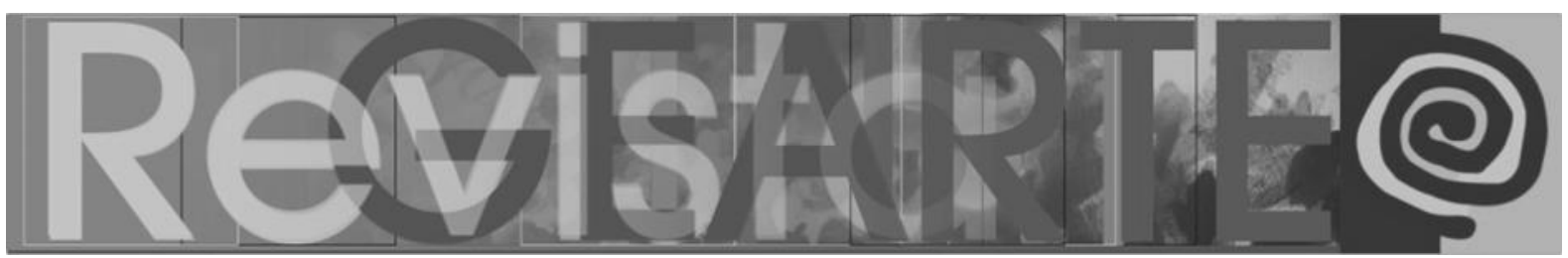

para las niñas y niños e incluso para las propias educadoras. Los trabajos fueron enviados a Tenerife, aunque solo Rita conocía en realidad a dónde se dirigían.

Figura 2 - Dibujos de MPBGC. Retrato de Elisa por Sofía (izquierda), retrato de Emilio por Mía (centro), retrato de Gustavo por Mathew (derecha)
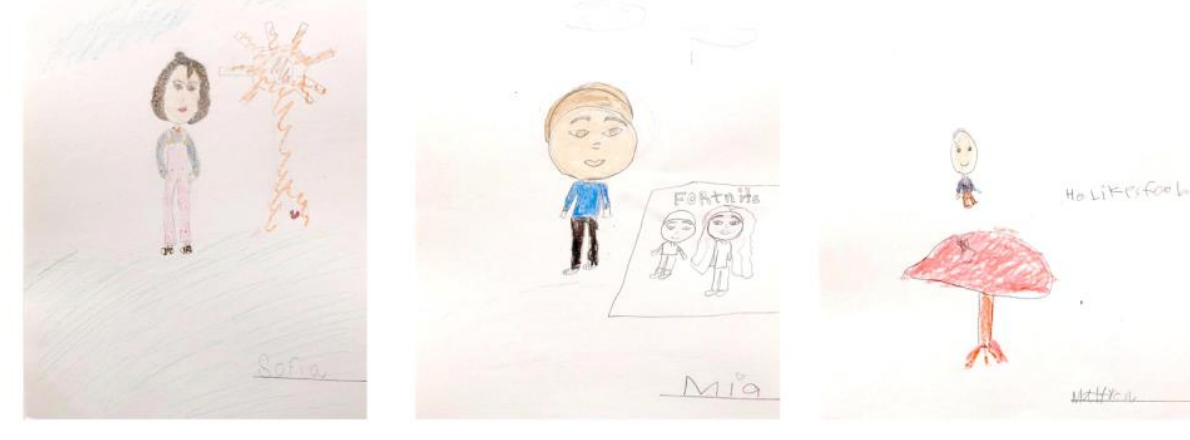

Fuente: Archivo de las autoras, 2019.

\section{Segundo encuentro: nos redescubrimos entre dibujos e imaginamos quiénes} nos dibujan

Una sesión más de las clases de la asignatura que impartía Noemí daba comienzo en la facultad. Todo era cotidiano, a excepción de toda una colección de dibujos situada en una de las paredes del aula y que inicialmente pasó inadvertida a ojos de los estudiantes. No es, sino a lo largo de un descanso, cuando una alumna se aproximó y descubrió su nombre y el del resto de compañeros y compañeras escritos en aquellos dibujos. Poco a poco se fueron descubriendo y comprobaron sorprendidos que aquellos retratos habían sido dibujados por personas cuyos nombres dejaron también escritos en los dibujos. Ante el asombro se preguntaron y cuestionaron la procedencia, el porqué de encontrar aquellos retratos allí, sin que obtuvieran información alguna.

Aquellos dibujos conectaban con cada uno, ya que los retratos desvelaban cómo somos vistos a través de nuestro nombre, formando parte sin pretenderlo de aquella autobiografía artística que construían. No podemos estar más de acuerdo 


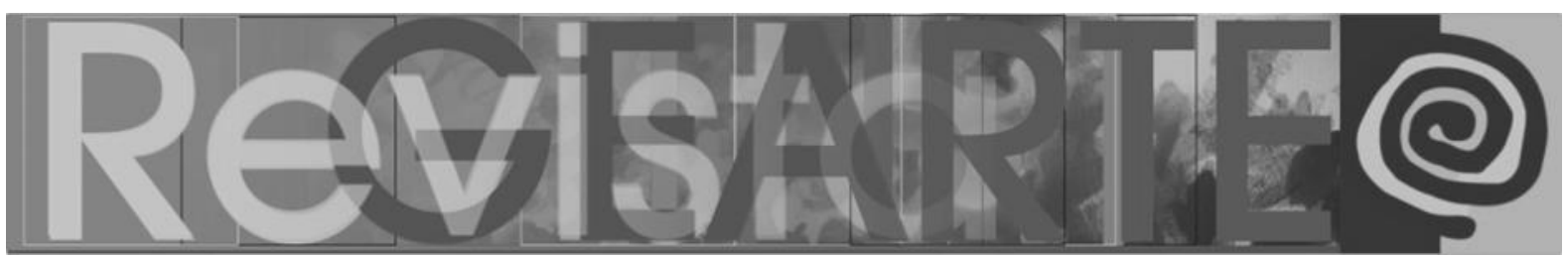

con esa idea de Hernández (2012, p. 70-71) puesto que "cada individuo tiene una percepción de sí mismo que puede o no ser coincidente con la que otros individuos o diferentes grupos tienen sobre ella".

Indudablemente, aquellos dibujos reclamaban una respuesta, así Noemí les propuso devolverles un retrato a aquellas personas que nos regalaron ese dibujo y de las que ya sabíamos sus nombres, al dejarlo escrito sobre cada retrato. Además, cada dibujo era en sí mismo huella y reflejo de quienes eran, ya que a través de los trazos, gestos y detalles de cada retrato podíamos advertir e imaginar rasgos que expresaban cosas sobre quien lo había creado. Inconscientemente los retratos revelaban elementos identitarios de las niñas y niños, al haber dibujado esos aspectos que les identificaban, tales como sus juegos favoritos o detalles que complementaban los retratos.

Fue muy enriquecedor descubrir las diferentes propuestas de retratos que los estudiantes universitarios realizaron, ya no solo por la variedad de lenguajes y recursos utilizados, sino porque de nuevo todos aquellos retratos desvelaban características de ellos y de ellas que la misma educadora desconocía. De nuevo el dibujo se convertía en un diálogo visual valioso.

Figura 3 - Dibujos de estudiantes de la ULL. Retrato de Sofía por Elisa (izquierda), retrato de Rosalíe por Emilio (centro), retrato de Matthew por Gustavo (derecha)
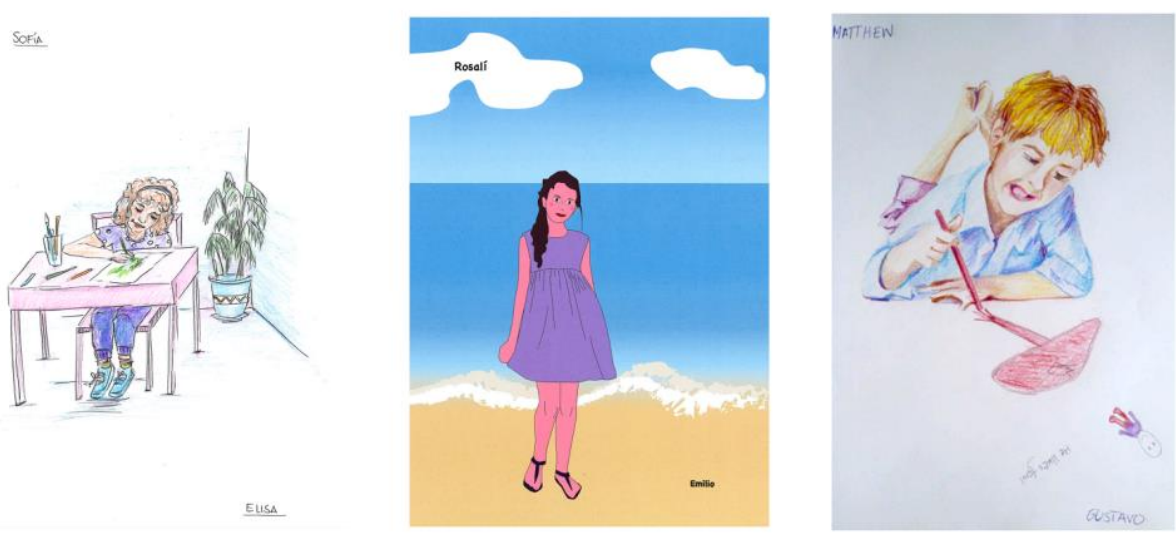

Fuente: Archivo de las autoras, 2019.

PEÑA-SÁNCHEZ, Noemí; NOGUERA RICARDI, Rita. Nombres retratados. 


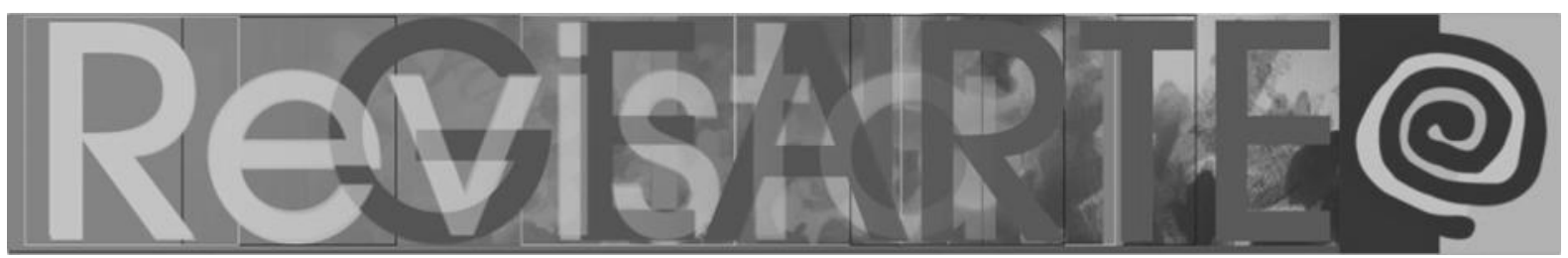

\section{Tercer encuentro: nuestro dibujo y nuestros retratos}

A MPBGC llegan sus nombres retratados. Se siguió la misma dinámica de ULL y se montó una exposición con sus dibujos y junto a ellos otros en los que habían retratado, eran en definitiva sus nombres retratados.

Figura 4 - Retrato de Alberto por Allan (izquierda), retrato de Allan por Alberto (centro), exposición de dibujos en el taller de MPBGC (derecha)

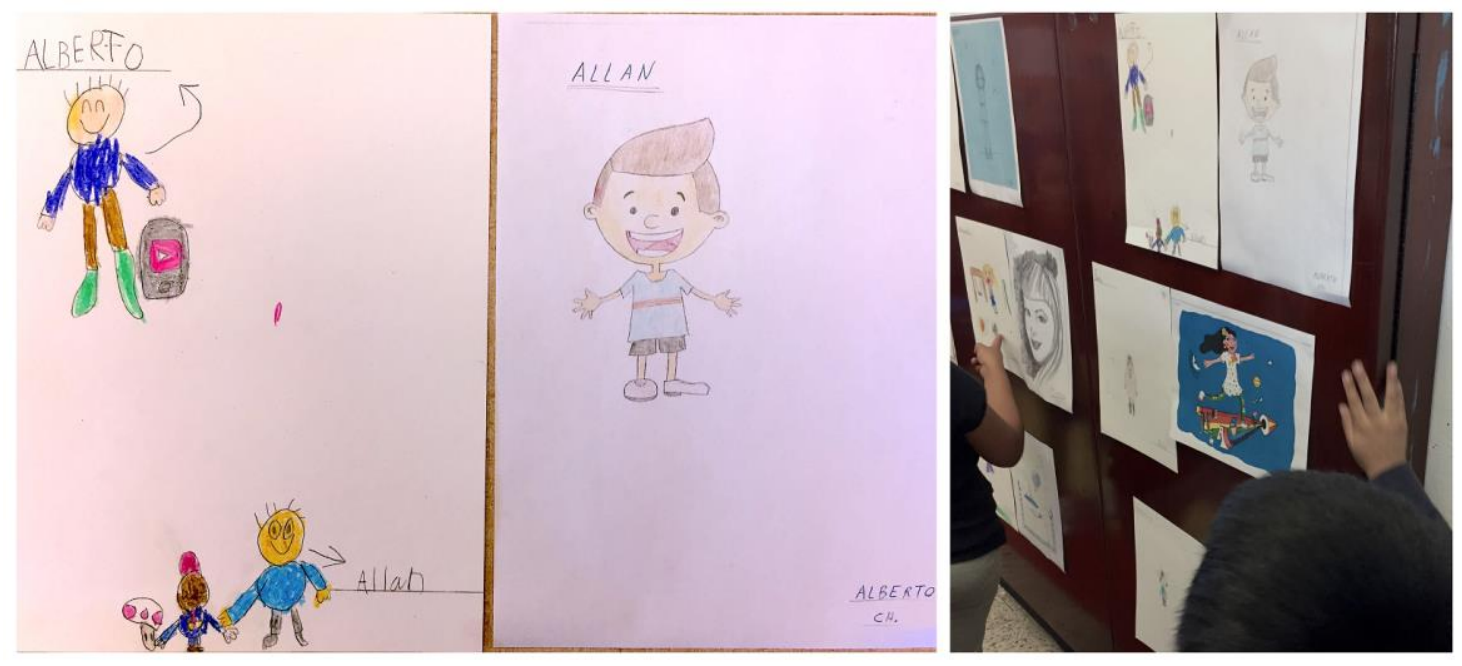

Fuente: Archivo de las autoras, 2019.

Cuando el taller comenzó los niños y niñas buscaban con curiosidad sus dibujos y con sorpresa reconocieron ciertas personas les habían retratado. Estos retratos revelaban que sus autores no eran niñas o niños y se escucharon comentarios como: "pero ellos dibujan muy bien"; "yo le dibujé feo y él a mi muy bonita"; "no me gusta cómo me ha dibujado"; "no soy yo"; "ha hecho mi pelo igual"; "qué bonito mi dibujo".

Se les preguntó qué edad creían que tenían las personas que les habían dibujado, algunos respondieron: "no son niños"; "30 años"; "60 años"; "20 años".

Se les lanzó otra pregunta: “¿dónde creéis que viven?”; "en Brasil”; "en México"; "en Guatemala". 


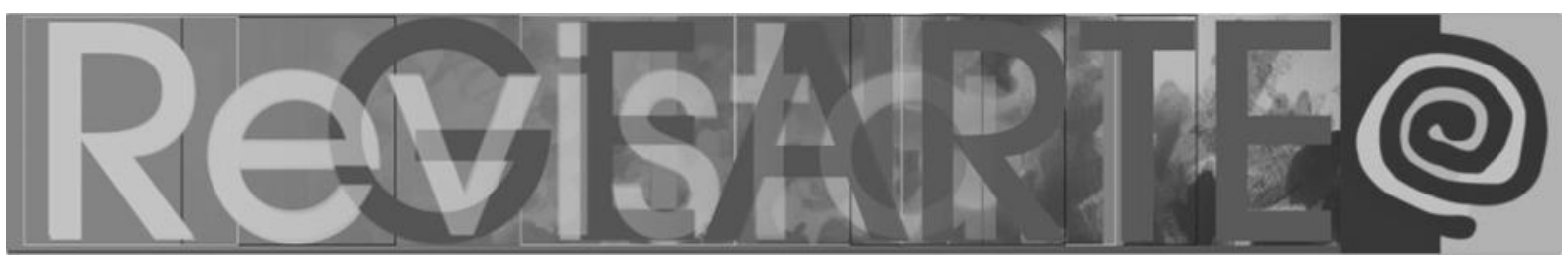

En primer lugar nombraron sus países de origen, pero después de mucho pensar una niña exclamó: “ison de España!”.

\section{Cuarto encuentro: la revelación de las identidades}

Sin duda era importante consensuar entre las educadoras la idea de cómo queríamos revelar las identidades que habían dibujado en los retratos. La fotografía como prueba y testimonio podía completar y aportar detalles fehacientes sobre quienes éramos. De este modo pensamos en preparar un siguiente encuentro adaptado a los ritmos y tiempos de cada contexto. En cada uno brindábamos todos aquellos retratos dibujados junto a un nuevo retrato fotográfico que desvelaba tal y como eran aquellas personas.

Figura 5 - Códigos QR con las grabaciones de audio de Rita y Noemí

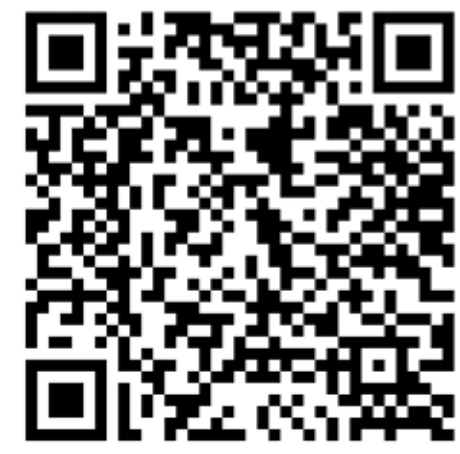

Escanea para escuchar a Rita

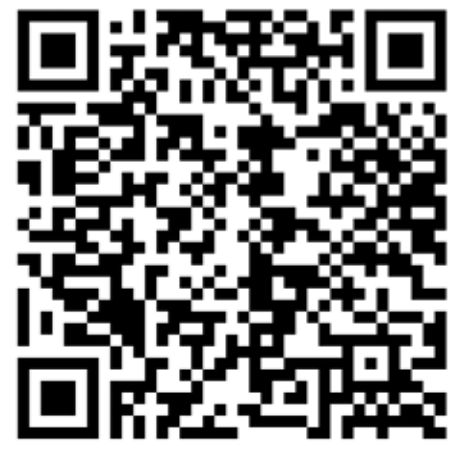

Escanea para escuchar a Noemi

Fuente: Archivo de las autoras, 2019.

Del mismo modo, nos parecía revelador compartir quién era la educadora de cada contexto y que había sido parte implicada en todo ese proceso. Nuestra presencia consistió en un testimonio oral de quienes éramos. 


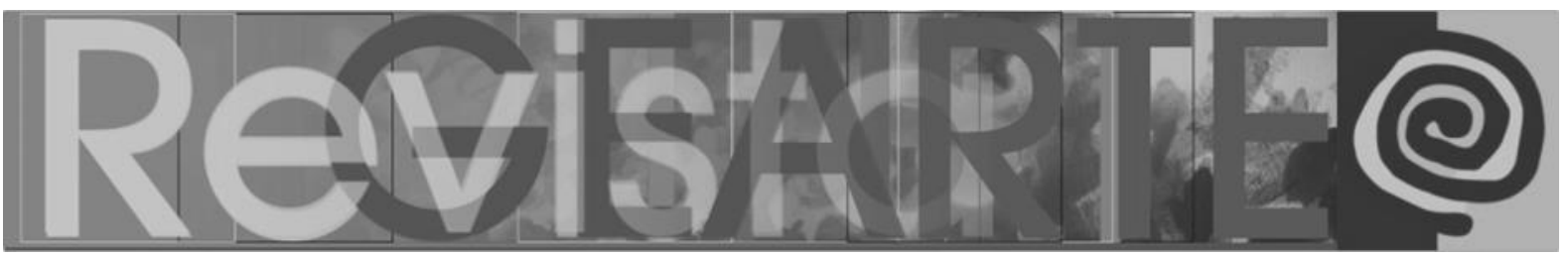

Figura 6 - Retrato de Bella por Sara (izquierda), retrato de Sara por Bella (centro), retrato fotográfico de Sara (derecha)
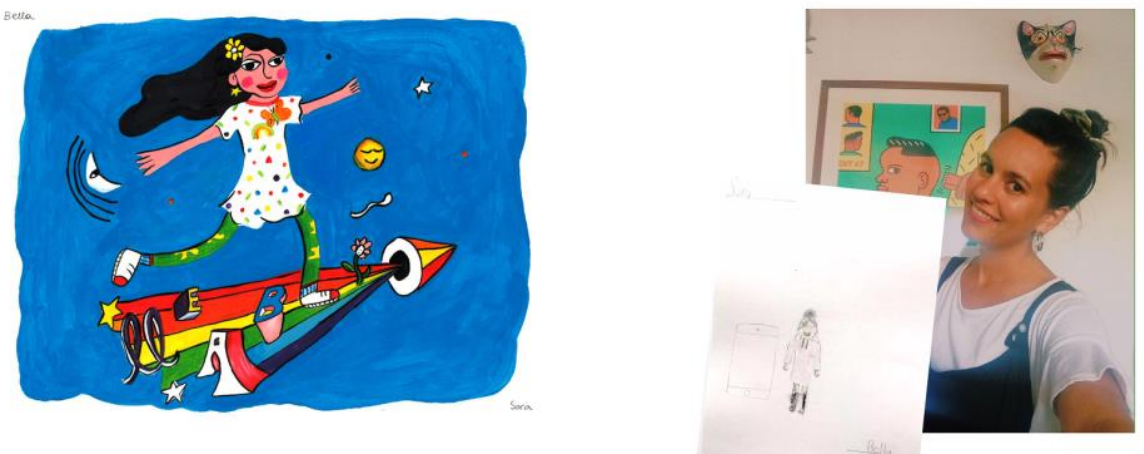

Fuente: Archivo de las autoras, 2019.

Era la última sesión de la asignatura en la facultad y con ella cerrábamos el periodo formativo del Máster, por este motivo aprovechamos el momento para desvelar la identidad de aquellas personas que nos retrataron. Para diseñar la exposición consideramos aportar una estructura similar para todas y todos, de forma que en las paredes del aula colocamos los retratos que recibieron inicialmente, debajo de estos estaban sus propios retratos y encima los retratos fotográficos en los que se podía observar a los autores de MPBGC sujetando el dibujo que nuestros estudiantes habían realizado.

\section{Figura 7 - Retrato de Sofía por Elisa (izquierda), retrato fotográfico de Elisa (centro) y retrato de Elisa por Sofía (derecha)}
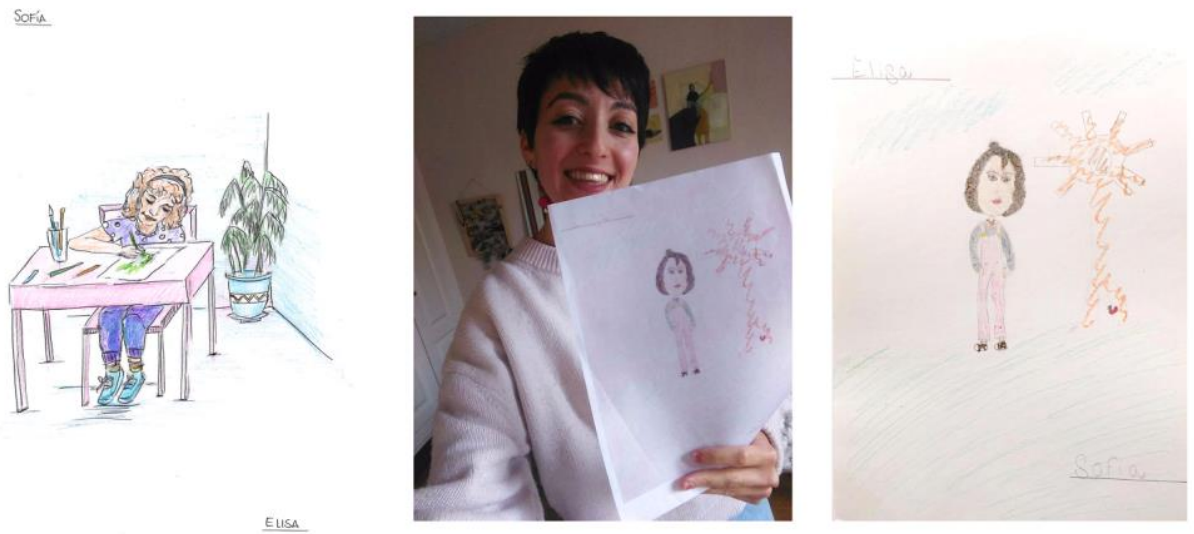

Fuente: Archivo de las autoras, 2019.

PEÑA-SÁNCHEZ, Noemí; NOGUERA RICARDI, Rita. Nombres retratados. 


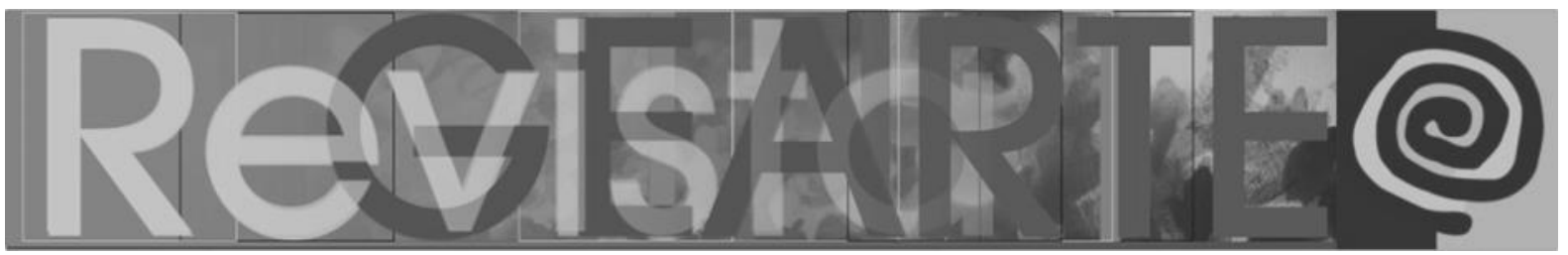

El espacio de la pared se convertía en un mosaico de retratos en los que podíamos advertir las características del grupo que había estado dialogando visualmente con nosotras y nosotros.

Como comentábamos anteriormente, quisimos incluir un retrato grupal en el que también conocimos a Rita, la educadora que había estado trabajando con el grupo. Ella nos dejó un relato con el que pudimos escuchar esa otra parte de la historia que desconocíamos. Los estudiantes se sorprendieron de que aquellos retratos hubieran venido de tan lejos ya que sus indagaciones les llevaban por territorios próximos a la isla.

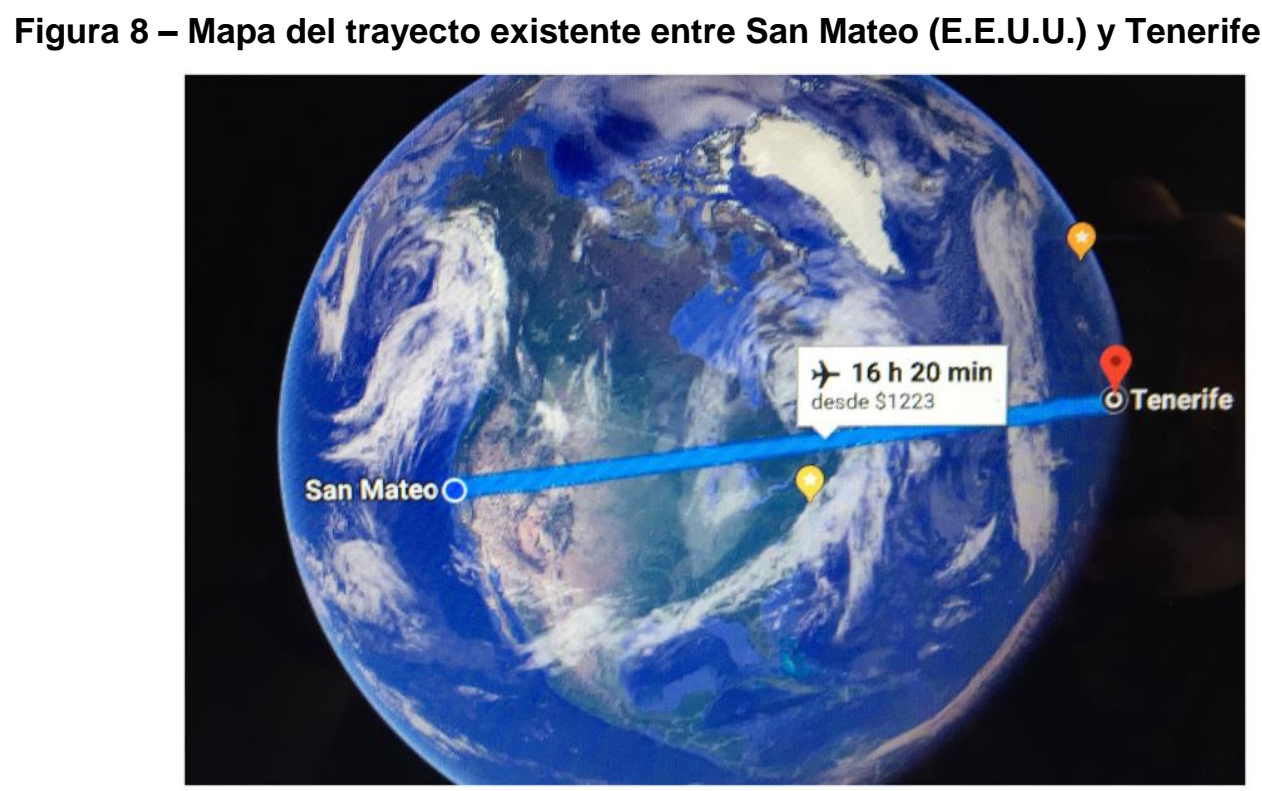

Fuente: Archivo de las autoras, 2019.

Situándonos en MPBGC, confirmamos que eran de España, concretamente de Tenerife, que forma parte de un grupo de islas llamadas Canarias y situadas fuera del territorio peninsular. Mostramos a las niñas y niños que si tomáramos un vuelo directo desde San Mateo a Tenerife llegaríamos en dieciséis horas.

Lo más llamativo para los niños y niñas fue el hecho de descubrir que aquellas personas con las que establecieron un diálogo visual eran estudiantes universitarios que se formaban como futuros docentes. 


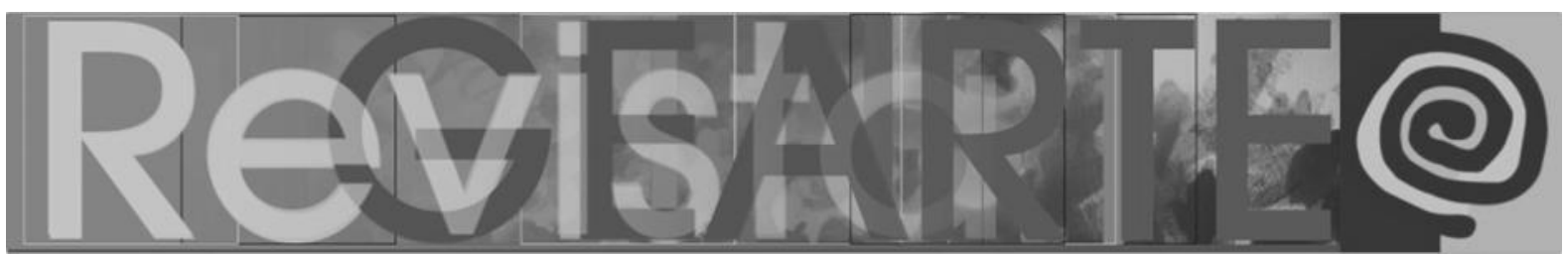

Como broche final hemos preparado un libro a cada uno de los participantes con las imágenes de sus dibujos en la cual desvelábamos los rostros de los autores de sus retratos.

Figura 9 - Libro individual Nombres retratados, registro del proceso (izquierda), Susan explorando su libro de Nombres retratados (derecha)

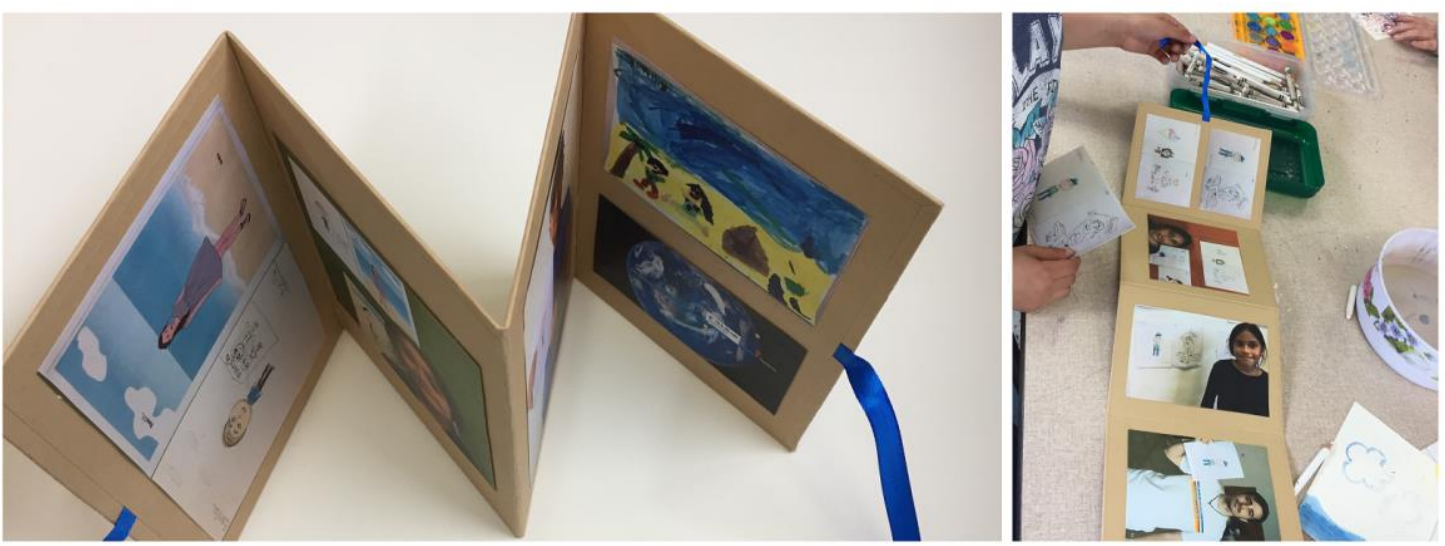

Fuente: archivo de Rita Noguera, 2019.

Toda la experiencia fue muy gratificante para todas y todos; la sorpresa era visible en las expresiones de los rostros de las niñas y de los niños. El hecho de encontrar los nombres retratados junto a las fotos de quienes lo habían dibujado fue revelador. Incluso al observar la similitud existente entre aquellos retratos imaginados y las fotografías en las que observábamos sus rostros.

Todo el dialogo visual fue fluido aún teniendo en cuenta el salto generacional existente entre ambos contextos. Comprobamos como brindar experiencias entre personas de edades y culturas diversas redescubre otros aprendizajes valiosos para la educación artística.

\section{Conclusiones}

Indudablemente, uno de los retos iniciales fue diseñar una propuesta común adaptada a las necesidades educativas de cada uno de los contextos implicados. En este sentido, el diálogo entre educadoras para compartir puntos de vista y reflexiones en torno a las prácticas artísticas fue clave para dotar de sentido al proyecto de Nombres retratados. Después de cada encuentro sentíamos la 


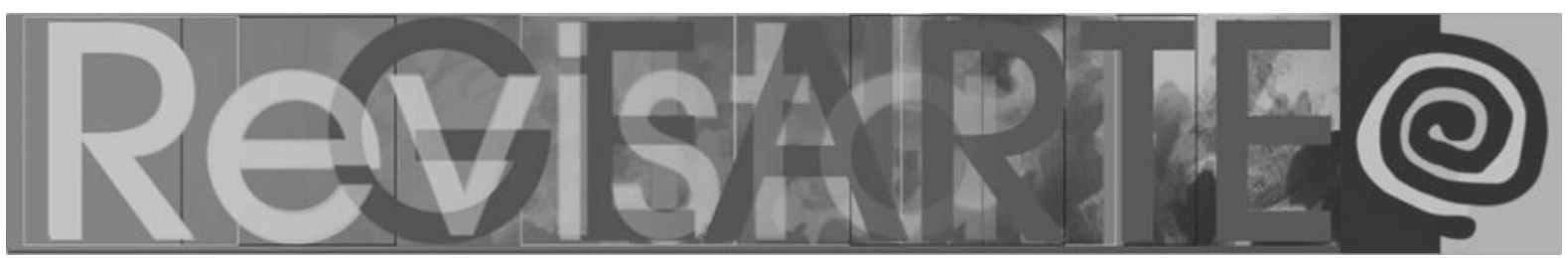

necesidad de compartir lo ocurrido, pues nos enseñaba a enlazar lo ocurrido con el encuentro siguiente. Aunque cada educadora trabajaba en su contexto, sentíamos como Nombres retratados nos llevaba a estar en aquel otro contexto, concibiéndolos como proyecto común en el que cooperábamos en desarrollar aquellas otras sesiones, aunque no estuviéramos presentes.

Como resultado podemos destacar la importancia de que los futuros educadores sean capaces de establecer diálogos con contextos educativos desconocidos para preparase para esa práctica docente con la que se encontrarán en su futuro próximo. El diálogo visual les ha llevado a adecuar sus retratos a las características de aquellas niñas y niños que les habían retratado. Sin duda, una de las ventajas de trabajar con generaciones diferentes ha sido desarrollar la empatía aprendiendo a comprender al otro, con la necesidad de ser capaz de dialogar visualmente y de forma accesible con aquella persona desconocida. Consideramos que esta relación empática es fruto de ese marco transgeneracional en el que se ha situado la experiencia.

Una de las limitaciones a mencionar ha sido el escaso tiempo para el desarrollo de un proyecto más extensivo, ya que tuvimos que adaptar cada encuentro a un calendario académico cerrado en el contexto universitario. Otra de las dificultades fue gestionar la variabilidad de participantes que asistían a los talleres de arte de MPBGC, ya que siempre contábamos con cierta incertidumbre sobre quienes asistirían al taller.

Para próximos proyectos sería interesante desarrollar una experiencia más extensiva que ampliara la indagación más allá del retrato y mantuviera la incertidumbre de las identidades involucradas.

La diversidad cultural de cada uno de los territorios y contextos implicados podría ser de gran interés para fomentar ese diálogo visual. Ese componente cultural aborda aspectos identitarios, así como sistemas de valores contenidos en cada cultura que modelan nuestra forma de percibir y vivir en el mundo. Para 


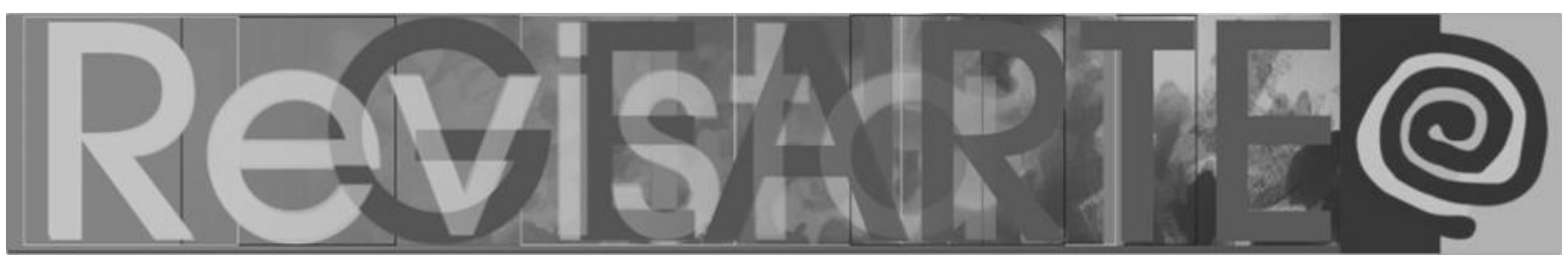

Andrus (2004) un educador debe ser competente culturalmente, y esto implica aceptar las diferencias existentes de cada cultura y sensibilizar a los otros sobre esa diversidad. Tenemos que ser capaces de adaptar nuestra práctica docente a las necesidades específicas del contexto atendiendo a todas esas subjetividades y enfocándolas como ventajas.

\begin{abstract}
Las identidades individuales y de grupo de una persona se forman por una comprensión histórica fundamental codificada y descrita en los constructos sociales, orales y escritos de una cultura específica. No comprenderlo supone no saber interpretar cuales son los aspectos identitarios de los estudiantes. (ANDRUS, 2004, p. 15)
\end{abstract}

Creemos que es importante brindar experiencias educativas en las que se involucren a personas con identidades diferentes, entendiendo esa diversidad cultural desde la complejidad de aspectos que se engloban y sin duda, porque esta conexión cultural construye historias que nos dejan huellas vitales y valiosas en nuestra memoria.

\title{
Referencias
}

ANDRUS, Lucy. The culturally competent art educator. Art Education, v. 54, n. 4, p. 14-19, 2004.

BANKS, James Albert; BANKS, Cherry A. McGee. Multicultural education: issues and perspectives. 7. ed. Nueva Jersey: John Wiley \& Sons, 2010.

HERNÁNDEZ, Fernando. Espigador@s de la cultura visual. 2. ed. Barcelona: Octaedro, 2012.

JIMÉNEZ, Lucina; AGUIRRE, Imanol; PIMENTEL, Lucia Gouvea. (Orgs.). Educación artística, cultura y ciudadanía. Madrid: Fundación Santillana/Organización de Estados Iberoamericanos, 2011.

MARTÍNEZ-NEAL, Juana. Alma y cómo obtuvo su nombre. Massachusetts: Candlewick Press, 2018.

MARTINEZ-NEAL, comunicación personal, 14 febrero, 2019.

STUHR, Patricia. L. A tale of why social and cultural content is often excluded from art education: and why it should not be. Studies in Art Education, v. 44, n. 4, p. 301-314, 2003.

\section{Noemí Peña-Sánchez}

Doctora en Bellas Artes por la Universidad Complutense de Madrid (UCM). Actualmente profesora del Departamento de Bellas Artes de la Universidad de La Laguna, área de Didáctica de la Expresión Plástica, donde desarrolla su labor docente en los grados de Bellas Artes y Educación Primaria, así como en el Máster de Formación del Profesorado en Educación Secundaria y Bachillerato en la especialidad de Dibujo, Diseño y Artes Plásticas. Su labor docente e investigadora aúnan intereses centrados especialmente en la enseñanza de las artes en contextos educativos

PEÑA-SÁNCHEZ, Noemí; NOGUERA RICARDI, Rita. Nombres retratados.

Historias dibujadas transfronterizas y transgeneracionales.

Revista GEARTE, Porto Alegre, v. 7, n. 1, p. 50-68, jan./abr. 2020.

Disponível em: http://seer.ufrgs.br/gearte 


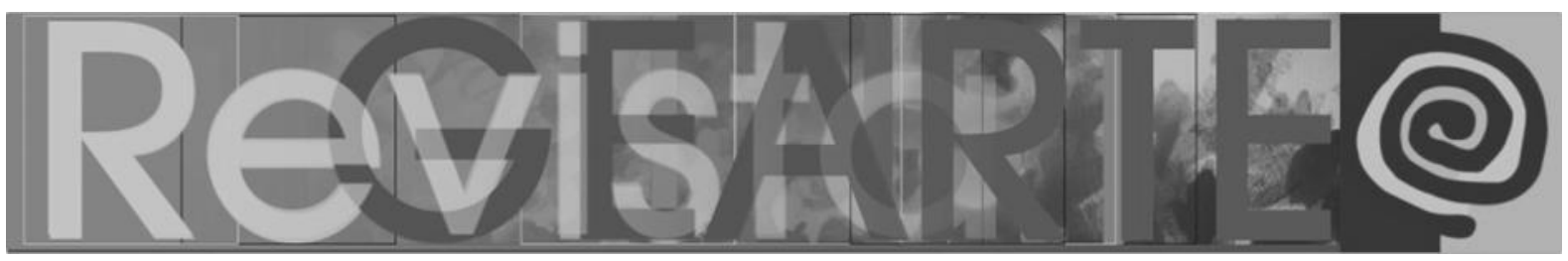

diversos con una implicación social, así como en los usos de la fotografía en los procesos de enseñanza y aprendizaje y en el arte comunitario.

ORCID: https://orcid.org/0000-0002-4792-2243

E-mail: npenasan@ull.edu.es

Currículo: https://www.researchgate.net/profile/Noemi_Pena_Sanchez2

\section{Rita Noguera Ricardi}

Licenciada en Educación Artística en la Universidad Estatal Paulista (UNESP). Especialización en Educación Artística por la Universidad Complutense de Madrid (UCM). Master en Pedagogía Sistémica - enfoque Bert Hellinger, Zentrum de Madrid. Cursos de formación continuada en la Universidad de Stanford de California. Coordinadora de talleres para niños, jóvenes, adultos, formación de profesores y de arte en familia, con más de 28 años de experiencia entre Brasil, España y Estados Unidos. Autora de libros didácticos de arte para la editora española Editorial SM.

ORCID: https://orcid.org/0000-0002-1788-838X

E-mail: noguerarita@gmail.com

Currículo: http://jugarconarte.weebly.com/perfil.html

Recebido em 30 de setembro de 2019 Aceito em 2 de dezembro de 2019 